\title{
Analysis of in situ and laboratory corrosion coupons
}

\author{
AJ Chambers National Institute for Occupational Safety and Health, USA
}

CB Sunderman National Institute for Occupational Safety and Health, USA

CC Clark National Institute for Occupational Safety and Health, USA

MJ Powers National Institute for Occupational Safety and Health, USA

\begin{abstract}
The corrosion of steel support components in the underground mine environment is a significant problem for the industry and has broad safety implications for mineworkers. The Spokane Mining Research Division (SMRD) of the National Institute for Occupational Safety and Health, located in Spokane, Washington, USA, is investigating the corrosion of ground support in underground metal mining. The goal of this research is to reduce risk to miner safety by preventing falls of ground caused by damaged ground support.

This research paper presents the findings of field studies at collaborating mines and includes installation of corrosion coupons, mineralogical analysis, Internet-of-Things atmospheric monitoring, and rock mass resistivity measurements. Data collected from these studies inform understanding of corrosion rate, the environmental aggressors and inhibitors affecting corrosion, and the development of proactive mitigation tactics. Laboratory studies at SMRD complement the field studies through further investigation of the effects of corrosion on ground support integrity. Representative samples of ground support members exposed to real and simulated mine environments were evaluated for pitting, stress corrosion cracking, and mass loss. The outcomes of this research are advancements in real-time monitoring of the status of ground support systems, enhanced knowledge that can help engineers to plan and design safer work environments, and improved ground support systems that will better resist challenging environmental conditions in mines.
\end{abstract}

Keywords: corrosion, coupons, resistivity

\section{Introduction}

As modern mining environments become increasingly deep, the accompanying underground stresses also increase, thus requiring traditional ground support techniques and materials to adapt. In response to these challenges, increasingly higher strength grades of steel have been used to meet the increasingly demanding requirements placed on rockbolts in underground mines (Elias et al. 2013). However, the benefits of these higher-quality support elements have often been negated in highly corrosive mining environments. Corrosion has been credited with $29 \%$ of all rockbolt failures and $25 \%$ of all cable bolt failures associated with rockfalls in the Australian mining industry (Potvin et al. 2001). In addition to compromised support capabilities, the economic impact of rehabilitation of mining ground support can run into the tens of millions of dollars as uncertainty regarding the condition of ground support leads to potentially unnecessary replacement of large sections. Rehabilitation is costly in terms of materials, reassignment of personnel and equipment, and restricted mine access (Hassell 2008).

Whereas research has been conducted in the international mining industry, particularly in Australia and Canada, mining corrosion research in the United States has been limited. The National Institute for Occupational Safety and Health Spokane Mining Research Division (SMRD) seeks to reduce the number of corrosion-related rockfall injuries and fatalities through research and collaborations with the mining industry. Additionally, the SMRD seeks to fill a gap in mining corrosion research by focusing on hollow-core friction stabilising bolts as opposed to more commonly studied solid-core bolts. This research will be of 
particular importance to the hard rock mining industry, especially in ground conditions more appropriately managed with friction stabilising bolts.

\section{Methodology}

\section{$2.1 \quad$ Laboratory}

The corrosion rate is the speed at which a metal deteriorates in a given environment. This rate is measured using sacrificial coupons, which are small samples of the base component or material harvested to serve as test proxies. Coupons are installed in the environment or a simulated environment and allowed to corrode over time, after which the mass loss is measured. Knowing this rate could be useful in mine planning and rehabilitation. The corrosion rate measurement that SMRD has designed for friction stabiliser coupons seeks to accurately predict corrosion rate in a simulated environment by including a method of applying stresses to the coupon and replicating the mine atmospheric environment. In determining the corrosion severity, the coupons were measured for mass loss (ASTM International 2011b), hardness (ASTM International 2013b), pit density and maximum pit depth (ASTM International 2013a), after periods of 3, 6 and 12 months.

Friction bolt coupons were developed by cutting the standard bolt into $1.25 \mathrm{~cm}(0.5 \mathrm{in})$ sections. The coupons were prepared by slightly compressing the ring radially and welding the two flanges together, as shown in Figure 1. This process simulates the stress experienced by the bolt upon insertion into a slightly smaller hole during installation, according to ASTM International (2016). The welded wire mesh coupons were analysed for corrosion severity through mass loss and tension testing in accordance with ASTM International (2011a).

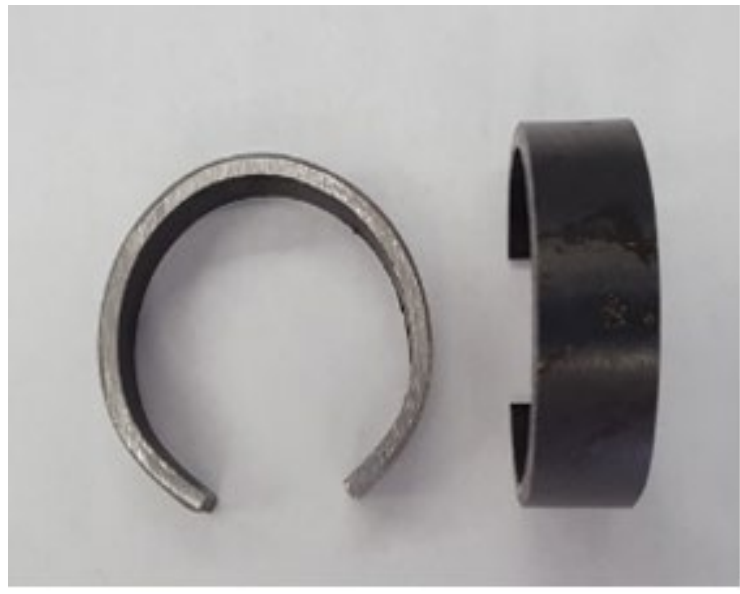

(a)

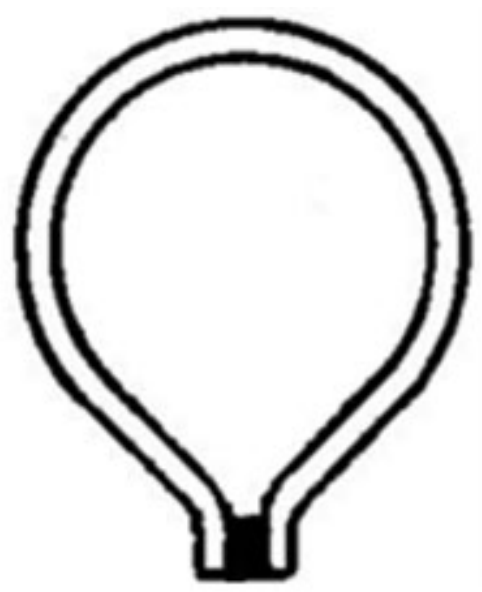

(b)

Figure 1 (a) Sections of bolt before welding; (b) Welded coupon diagram from ASTM G30 (ASTM International 2016)

To replicate the mine's atmospheric environment, both the bolt and mesh coupons were placed in bins of crushed rock samples of various mineralogies collected from the mine (Figure 2). Mesh coupons were similarly prepared by cutting them into smaller sections, but they were not placed under stress. These coupons were then placed in a fog room with a constant temperature of $21^{\circ} \mathrm{C}$ and $100 \%$ humidity to simulate the atmospheric conditions of the mine environment (Table 1). 


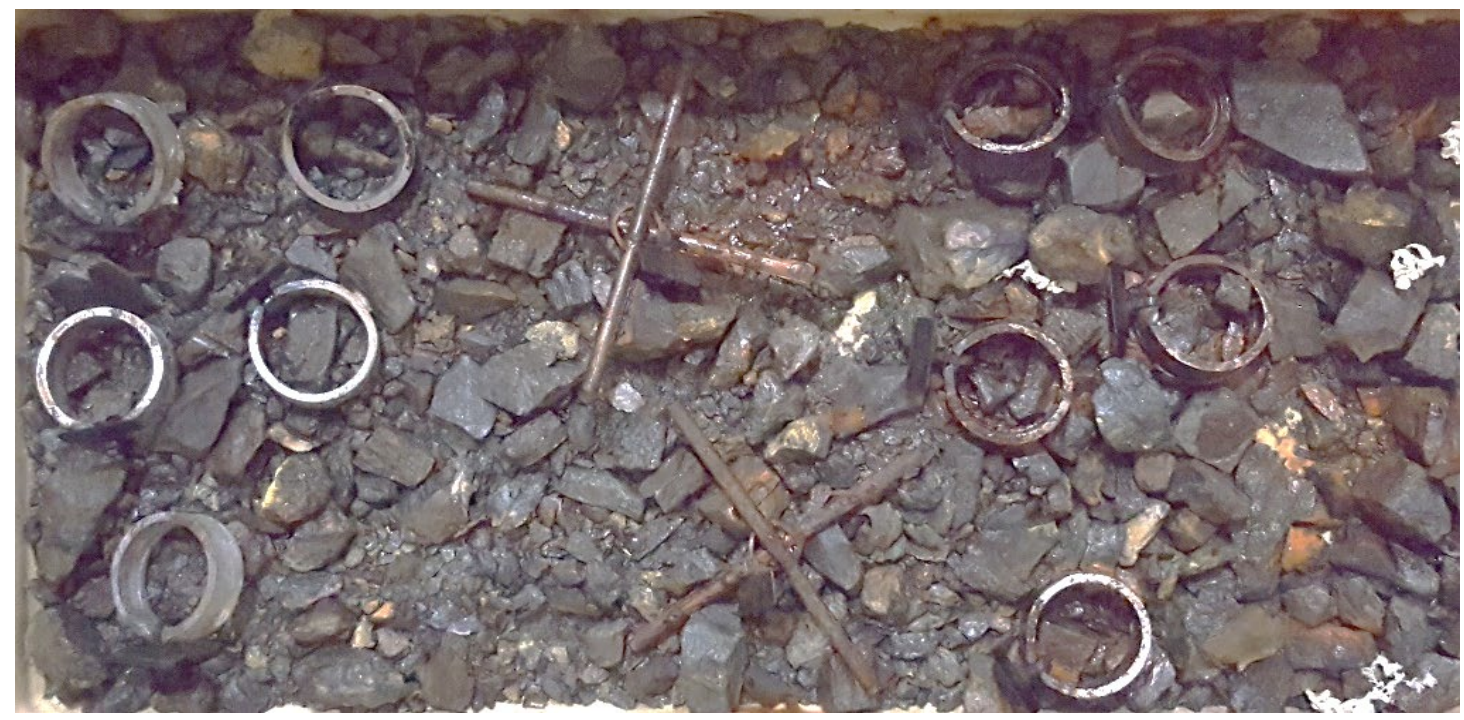

Figure 2 Sample container holding crushed rock and coupons after removal of first set

Table 1 Conditions of test. Sample Set 18 was a control in the fog room with no rock, and Sample Set 19 was a control outside the fog room with no rock

\begin{tabular}{|c|c|c|c|c|c|c|c|c|}
\hline \multicolumn{9}{|c|}{ Fog room baseline conditions } \\
\hline Sample & Temp & Humidity & \multicolumn{2}{|l|}{ Stress } & \multicolumn{4}{|c|}{ Crushed rock } \\
\hline $1-18$ & $21 \mathrm{C}$ & $100 \%$ & \multicolumn{2}{|c|}{ Bolt coupons only } & \multicolumn{4}{|c|}{ Various mineralogies outlined below } \\
\hline 19 & $21 \mathrm{C}$ & $20 \%$ & \multicolumn{2}{|c|}{ Bolt coupons only } & \multicolumn{4}{|c|}{ No rock exposure } \\
\hline \multicolumn{9}{|c|}{ Mineral analysis } \\
\hline Sample & $\mathrm{Cl} \%$ & C-Total \% & C-Graph \% & C-Organic \% & $\mathrm{CO}_{2} \%$ & Total S \% & $\mathrm{SO}_{4} \%$ & pH \\
\hline 1 & 0.03 & 1.09 & 0.06 & 0 & 2.88 & 1.63 & 4.03 & 5.53 \\
\hline 2 & 0.01 & 6.87 & 0.36 & 0 & 22 & 1.42 & 1.45 & 6.3 \\
\hline 3 & 0.02 & 7.69 & 1.42 & 0.8 & 19.9 & 1.12 & 1.19 & 6.44 \\
\hline 4 & 0.02 & 8.67 & 1.18 & 0.6 & 25.1 & 0.71 & 0.83 & 6.78 \\
\hline 5 & 0.01 & 8.4 & 1.81 & 0.7 & 21.7 & 0.85 & 0.62 & 7.25 \\
\hline 6 & 0.01 & 2.59 & 0 & 0 & 9.41 & 1.78 & 1 & 7.32 \\
\hline 7 & 0.01 & 2.93 & 0.13 & 0 & 10.2 & 7.37 & 4.33 & 5.66 \\
\hline 8 & 0.01 & 2.1 & 0 & 0 & 7.7 & 1.52 & 0.71 & 6.34 \\
\hline 9 & 0.01 & 4.73 & 1.01 & 1.3 & 8.71 & 2.4 & 3.5 & 2.56 \\
\hline 11 & 0.01 & 1.36 & 0 & 0 & 4.72 & 10.6 & 5.44 & 5.45 \\
\hline 12 & 0.02 & 7.41 & 1.29 & 1 & 18.8 & 3.08 & 3.51 & 6.11 \\
\hline 13 & 0.01 & 8.28 & 1.91 & 0.8 & 20.4 & 2.1 & 1.38 & 6.51 \\
\hline 14 & 0.01 & 8.44 & 1.56 & 0.9 & 21.7 & 1.04 & 1.38 & 7.01 \\
\hline 15 & 0.02 & 8.49 & 2.44 & 0.8 & 19.3 & 1.02 & 0.8 & 7.53 \\
\hline 16 & 0 & 3.44 & 0.18 & 0 & 10.9 & 1.91 & 1.07 & 7.31 \\
\hline 17 & 0.01 & 8.42 & 1.81 & 0.6 & 21.9 & 1.59 & 2.06 & 7.3 \\
\hline
\end{tabular}


The crushed rock samples were also analysed for mineral content in order to understand the possible mineralogical effects on corrosion rate. This process entailed determining the chloride, sulphates, carbon dioxide and carbon content of the samples. To investigate further, carbon analysis was broken down to total carbon, graphitic carbon and organic carbon. Finally, to ensure a thorough suite of tests, the laboratory analysis also included rock sample pH measurements (ASTM International 2012). Table 1 outlines the baseline conditions and the mineral analysis of the different rock samples.

\section{$2.2 \quad$ Field}

In situ corrosive environments were studied at two collaboration mines by placing field coupons in representative locations based on qualitative assessments (Figure 3). The locations varied through increasing degrees of severity of corrosion from very low to severe.

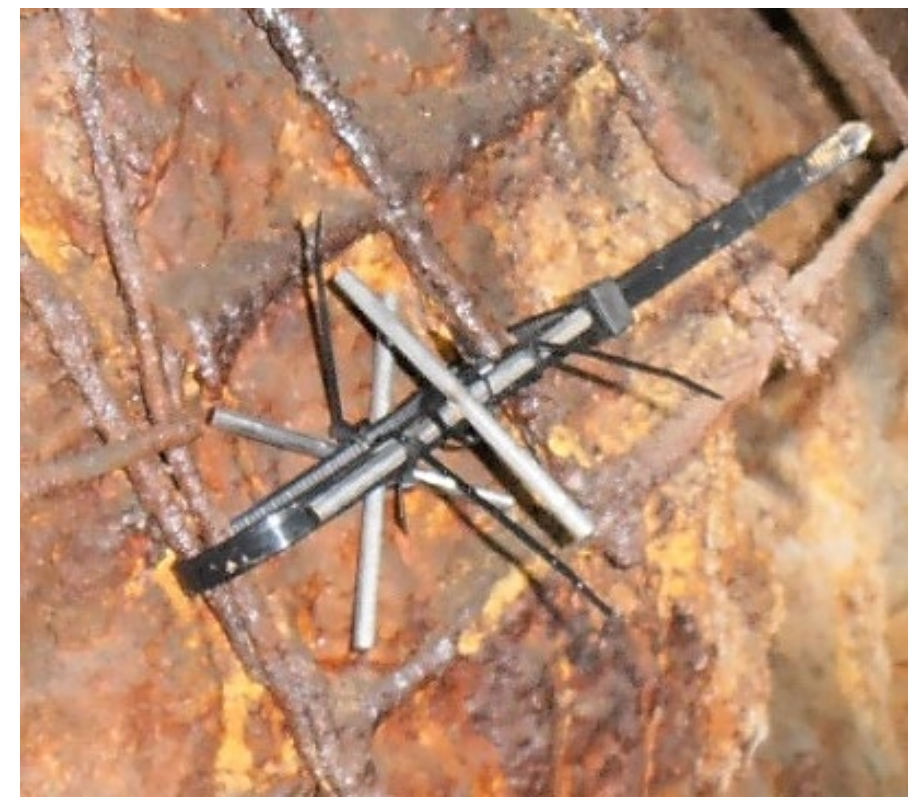

Figure 3 Welded wire mesh coupons in the field

The inputs defining the atmospheric conditions were temperature, humidity and time of wetness. These conditions were monitored in real time utilising newly developed SMRD surface wetness sensors and wireless data transmission technology. The sensors are an SMRD custom design incorporating commercial temperature and humidity sensors. The deployed mine sensors are manufactured on a standard printed circuit board and constructed such that the printed circuit board is placed upon the surface to be measured. Data from the sensors were transmitted in real time over a Dust Networks Smartmesh IP wireless sensor network to a test server on the internet. In this study, SMRD sensors were deployed in areas immediately adjacent to the emplaced coupons (Figure 4). This technology allows mine personnel to have real-time data with which to make informed decisions from calculated corrosion rates and in situ mine atmospheric conditions. 


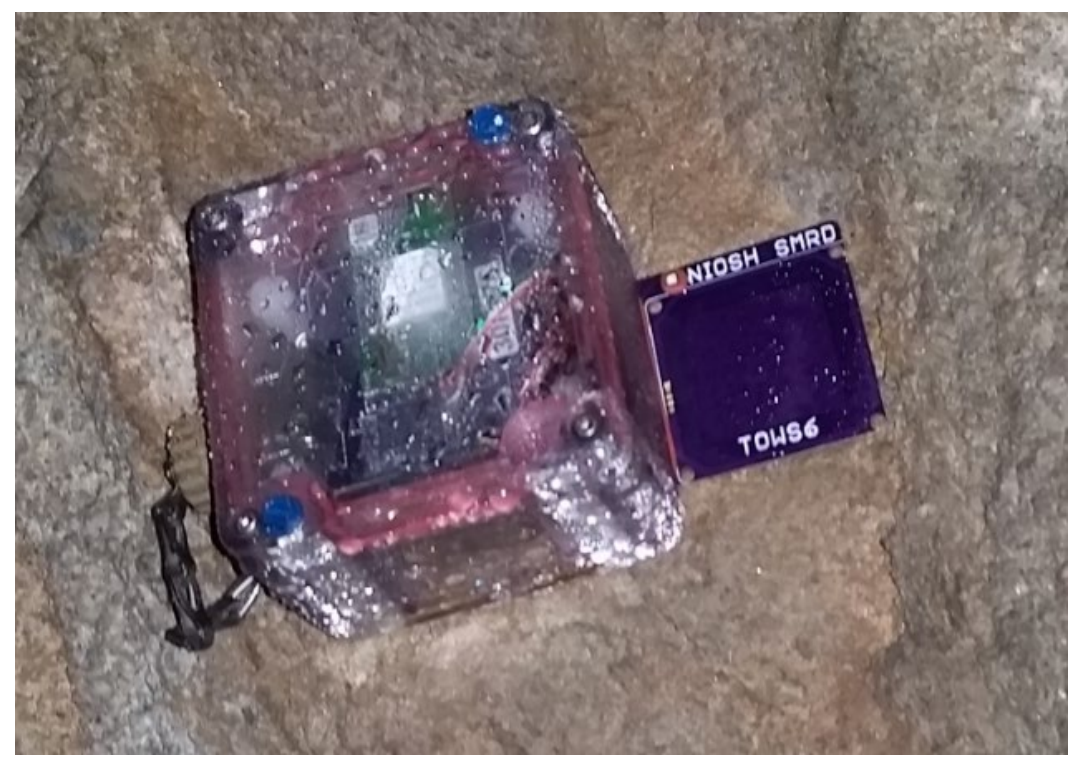

Figure 4 Atmospheric monitoring sensor in the field

The resistivity of the rock mass was measured at each welded wire mesh coupon location. In civil construction, it has long been known that soil resistivity is a primary indicator of soil corrosivity (Lewis \& Riggs Larsen 2017; Peabody 2001). The resistivity of concrete has also been correlated to corrosion control in reinforcement (Polder 2001, 2009). In order to investigate the viability of using these guidelines in mining, rock mass resistivity was measured using a Wenner Array (ASTM International 2005). The electrodes were installed by drilling four holes with $10.14 \mathrm{~cm}$ (4 in) spacing and inserting $7.62 \mathrm{~cm}(3 \mathrm{in})$ stainless steel construction screws as electrodes (Chambers et al. 2017). With the electrodes in place, a resistivity instrument measured both the current and voltage, calculating the resistivity using the following relationship:

$$
R=2 \pi a(V / I)
$$

where:

$$
\begin{aligned}
a & =\text { area. } \\
V & =\text { voltage } \\
l & =\text { current. }
\end{aligned}
$$

At the time of writing, the field coupons were still installed in the collaborating mines; therefore, results of the field coupons and sensors studies will be shared in a future paper. In the absence of field corrosion rate data, the resistivity measurements were compared with qualitative assessments of corrosion severity.

\section{$3 \quad$ Results}

\subsection{Laboratory study results: corrosion rate, mineralogy and pull testing}

Analysis of the laboratory coupons did not reveal any statistically significant correlations between the severity of corrosion metrics (mass loss, pit density, pit depth, and hardness) and the rock mass analysis. As demonstrated in Figure 5, relationships showed large data scatter, where at either $0 \%$ or $1.3 \%$ organic carbon, pits in varied densities could occur. 


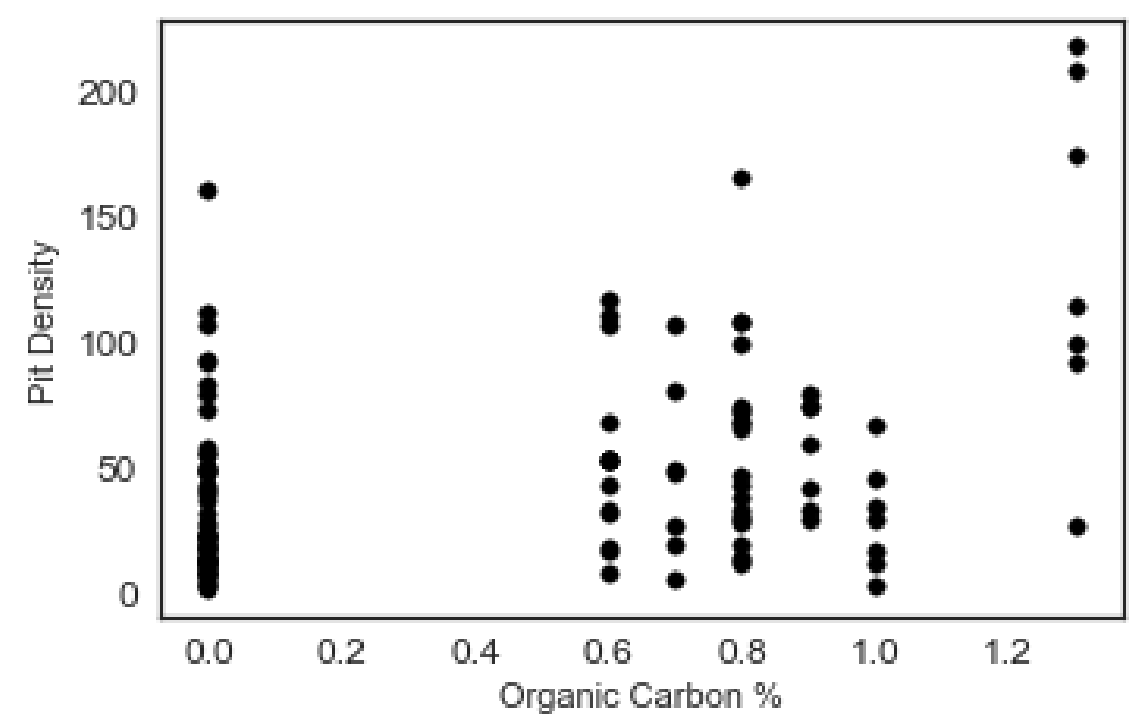

Figure 5 Relationship of organic carbon percentage on corrosion pit density

Additionally, tensile testing of laboratory mesh coupon samples did not reveal any statistically significant correlations between mineralogy and effect of corrosion on coupon integrity (strain \% and breaking force). Figure 6 demonstrates the variability in $\mathrm{Cl} \%$ and strain \%.

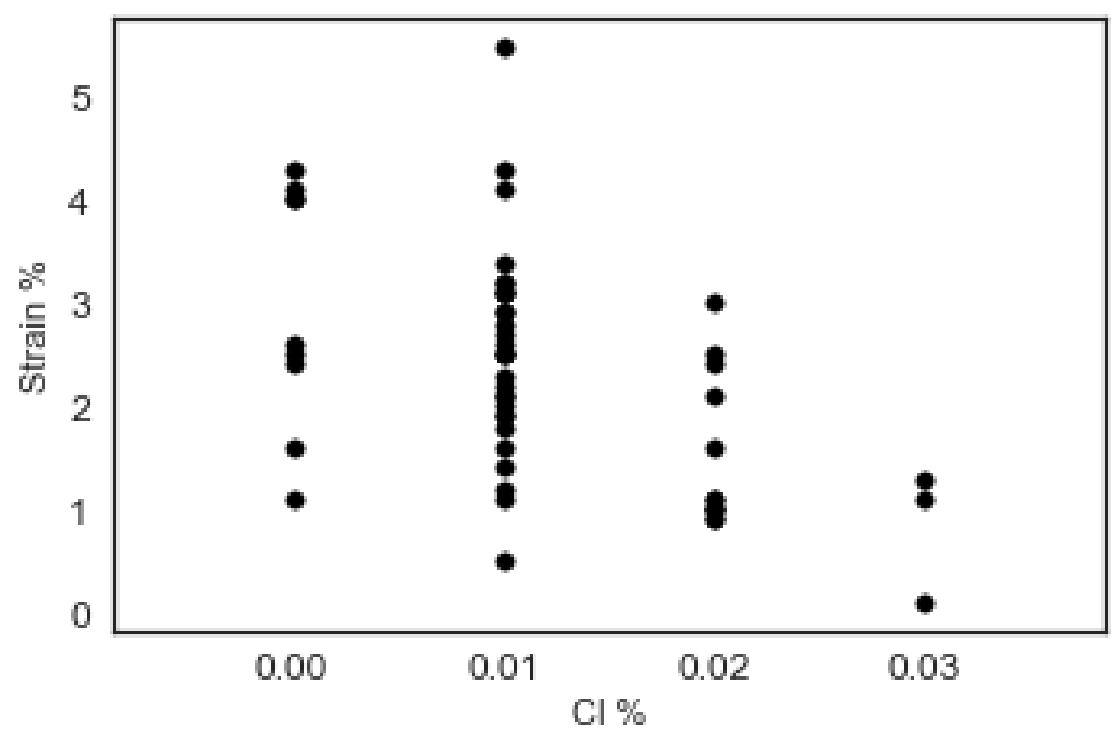

Figure 6 Effect of the $\mathrm{Cl}$ percentage in the rock minerals on the strain percentage of welded wire mesh

\subsection{Field study results: rock mass resistivity}

Using a qualitative method developed by Dorion \& Hadjigeorgiou (2014) for assessing corrosion severity in ground support, SMRD researchers found that rock mass resistivity data from both mines did indeed indicate that rock with lower facilitates higher levels of corrosion. This finding is shown in Figure 7, where soil and concrete resistivity guidelines along with this study's hard rock resistivity data are compared to degree of corrosivity. The measured resistivity of the hard rock suggests that guidelines for soil may not be suitable for use in underground mining but that the range used for concrete appears to be appropriate. Researchers are seeking to collaborate with more mines to verify the relationship of resistivity and corrosivity in a variety of mineralogies and rock mass ratings common to hard rock mining. 


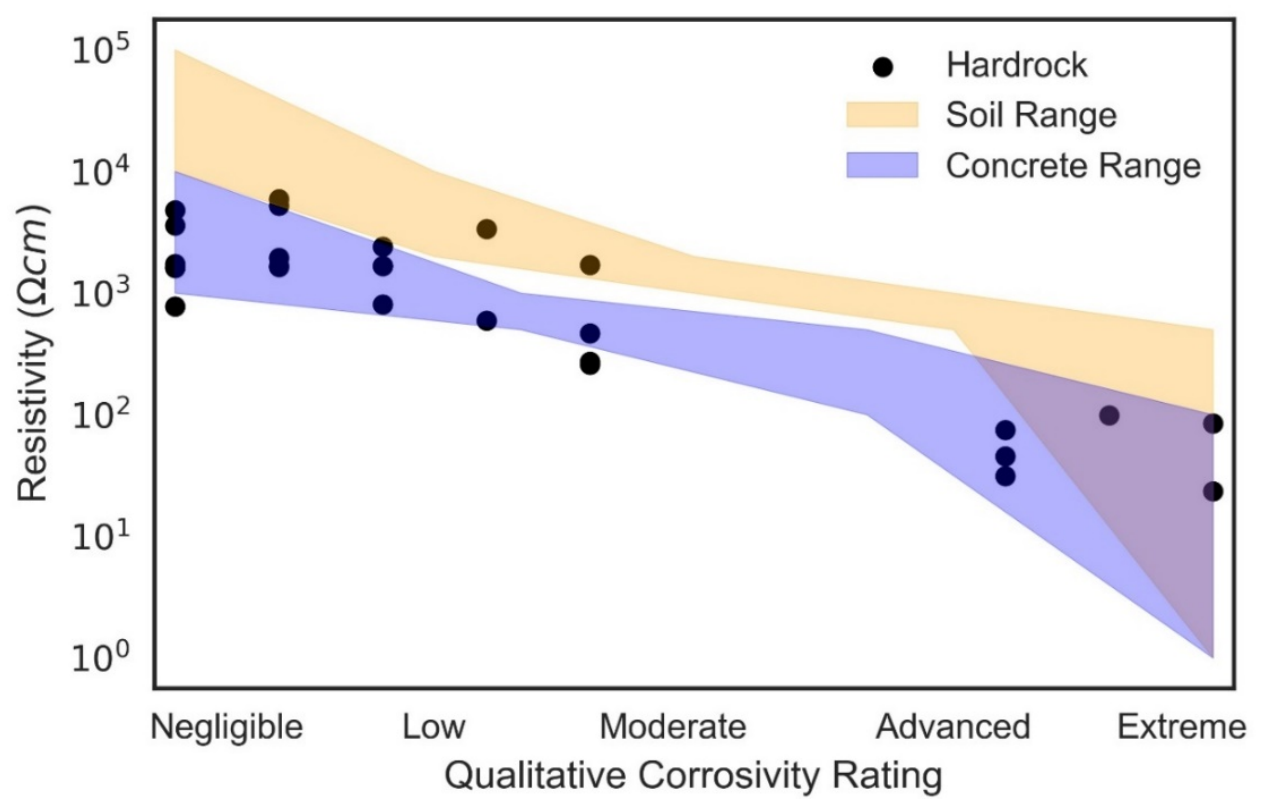

Figure 7 Concrete resistivity ranges could be used to forecast corrosion severity in rock mass

\section{Conclusion}

The corrosion rate experienced by both mesh and bolt coupons under the test conditions did not produce any correlations to mineralogy. Field observations continue to suggest that corrosion rate as a function of resistivity depends on local rock mass formation. These locality influences appear to be present in the original location only. Testing in the laboratory environment in absentia of actual rock mass influences does not produce the same electromagnetic environment. Future testing in a laboratory should be designed with a more in-depth understanding of the global rock mass electromagnetic forces and the local conditions, such as mineralisation, temperature, and humidity previously captured.

Researchers have, however, found correlations in rock mass conductivity and corrosion severity. With the development of field-deployable instrumentation, a mine can develop a true index quantified by spot testing in the mine at key locations and build a corrosivity ground control plan for rehabilitation or proper first-installation guidelines. Sensors and monitoring are also showing promise, with real-time data sets and logging of changing mine environments at key test locations.

\section{Acknowledgement}

Much of this research was conducted in Hecla's Greens Creek mine. The work and cooperation of the mine engineers are much appreciated. SMRD thanks Mark Board for initiating this research project, Montana Technical University for its collaboration and insights, and Jennmar for providing welded wire mesh and bolt samples.

\section{Disclaimer}

The findings and conclusions in this report are those of the author(s) and do not necessarily represent the official position of the National Institute for Occupational Safety and Health, Centers for Disease Control and Prevention. Mention of any company or product does not constitute an endorsement by the National Institute for Occupational Safety and Health, Centers for Disease Control and Prevention. 


\section{References}

ASTM International 2005, Standard Guide for Using the Direct Current Resistivity Method for subsurface Investigation (ASTM D6431), ASTM International, West Conshohocken.

ASTM International 2011a, Standard Practice for Preparation and Use of Direct Tension Stress-Corrosion Test Specimens (ASTM G4985(2011)), ASTM International, West Conshohocken.

ASTM International 2011b, Standard Practice for Preparing, Cleaning, and Evaluating Corrosion Test Specimens (ASTM G1-03), American Society for Testing and Materials, West Conshohocken.

ASTM International 2012, Standard Test Method for Measuring pH of Soil for Use in Corrosion Testing (ASTM G51-95(2012)), ASTM International, West Conshohocken.

ASTM International 2013a, Standard Guide for Examination and Evaluation of Pitting Corrosion (ASTM G46-94(2018)), ASTM International, West Conshohocken.

ASTM International 2013b, Standard Hardness Conversion Tables for Metals Relationship Among Brinell Hardness, Vickers Hardness, Rockwell Hardness, Superficial Hardness, Knoop Hardness, Scleroscope Hardness, and Leeb Hardness (ASTM E140-12b, ASTM International, West Conshohocken.

ASTM International 2016, Standard Practice for Making and Using U-Bend Stress-Corrosion Test Specimens (ASTM G30-97(2016), ASTM International, West Conshohocken.

Chambers, AJ, Sunderman, CB, Benton, DJ, Brennan, JT \& Orr, DT 2017, 'Evaluation and mapping of corrosion in a Western USA underground metal mine-year one preliminary results', in J Wesseloo (ed.), Proceedings of the Eighth International Conference on Deep and High Stress Mining, Australian Centre for Geomechanics, Perth, pp. 785-798.

Dorion, JF \& Hadjigeorgiou, J 2014, 'Corrosion considerations in design and operation of rock support systems', Mining Technology, vol. 123 , no. 2, pp. 59-68.

Elias, E, Vandermaat, D, Craig, P, Chen, H, Crosky, A, Saydam, S, Hagan, P \& Hebblewhite, B 2013, 'Metallurgical examination of rockbolts failed in service due to stress corrosion cracking', in Y Potvin \& B Brady (eds), Proceedings of the Seventh International Symposium on Ground Support in Mining and Underground Construction, Australian Centre for Geomechanics, Perth, pp. 473-483.

Hassell, R 2008, Corrosion of Rock Reinforcement in Underground Excavations, PhD thesis, Curtin University of Technology, Bentley.

Lewis, M \& Riggs Larsen, K 2017, 'Historic corrosion tools tell the story of early corrosion control', Materials Performance: Corrosion Prevention and Control Worldwide, vol. 56.

Peabody, AW 2001, Peabody's Control of Pipeline Corrosion, 2nd edn, NACE International, Houston.

Polder, RB 2001, 'Test methods for on site measurement of resistivity of concrete-a RILEM TC-154 technical recommendation', Construction and Building Materials, vol. 15, no. 2, pp. 125-131.

Polder, RB 2009, 'Critical chloride content for reinforced concrete and its relationship to concrete resistivity', Materials and Corrosion, vol. 60, no. 8, pp. 623-630.

Potvin, Y, Nedin, P, Sandy, M, Rosengren, K \& Rosengren, M 2001, Towards the Elimination of Rockfall Fatalities in Australian Mines, Australian Centre for Geomechanics, Perth. 